\title{
A ALTERIZAÇÃO DA MULHER NO PROJETO NACIONAL IRLANDÊS
}

\author{
RAIMUNDO EXPEDITO DOS SANTOS SOUSA \\ Universidade Federal de Minas Gerais (UFMG) \\ ADELAINE LAGUARDIA \\ Universidade Federal de São João del-Rei (UFSJ)
}

\section{RESUMO}

O anticolonialismo irlandês pautou-se na maximização de fronteiras de gênero com vistas a acentuar a hombridade dos homens gaélicos em face de sua feminização pelo colonialismo inglês, que se legitimava pela atribuição de gênero ao vínculo entre Inglaterra e Irlanda ao inscrever o império no registro masculino e a colônia no feminino. Mediante pesquisa em fontes primárias, investigamos as implicações dessa contra-estratégia na representação de mulheres subversivas que desafiavam uma matriz de gênero dual em que a masculinidade se definia em relação oposicional e complementar com a feminilidade. Tanto as feministas, que antepunham sua agenda ao nacionalismo, quanto as republicanas, que defendiam a nação antes com o rifle do que com o rosário, eram "alterizadas" pela intelligentsia nacionalista como aberrações de gênero por meio de descrições caricaturais que mal escamoteavam o temor de sua transgressão desestabilizar as balizas de gênero que sustentavam 0 projeto de remasculinização nacional.

PALAVRAS-CHAVE: Irlanda; Projeto Nacional; Mulheres; Alterização.

\section{ABSTRACT}

Irish anticolonialism was based on the maximization of gender boundaries in order to accentuate the manliness of Gaelic men against their feminization by a colonialism that legitimized itself attributing gender to the link between England and Ireland, inscribing the empire in male register and the colony in the female one. Through research in primary sources, we investigate the implications of this counter-strategy in the representation of subversive women who challenged a dual gender matrix in which masculinity is defined in oppositional and complementary relation with femininity. Both feminists, who privileged their policies instead of nationalism, and Republicans, who defended the nation with the rifle rather than with the rosary, were othered by the nationalist intelligentsia as gender aberrations in sardonic descriptions whose scorn hardly hide the fear their transgression could destabilize gender boundaries that supported the project of national remasculinization.

KEYWORDS: Ireland; National Project; Women; Othering. 


\section{Introdução $^{1}$}

Na colonização da Irlanda, o imperialismo inglês adotou uma economia geopolítica bidimensional de "racialização" do gênero e "generização" da raça ao instaurar um regime de representação bipolar que masculinizava o império e feminizava a colônia, a fim de naturalizar o vínculo colonial e chancelar sua configuração assimétrica sob os álibis da complementaridade e hierarquia "naturais" entre os sexos, além de convencer os irlandeses de sua efeminação e, assim, mutilar seu potencial insurrecional. Como a resistência é a contraface do poder, os colonizados reagiram ao travar, de um lado, batalhas literais pela autonomia política e, de outro, batalhas simbólicas pela sua autorepresentação. Todavia, já que não ocupavam na dialética colonial as mesmas posições estatuárias que os colonizadores, precisaram fazê-lo sob limites discursivos circunscritos pelos últimos, de modo que a consolidação de uma identidade nacional irlandesa pretensamente genuína dependeria, a rigor, da ambivalente dinâmica de contra-significação na qual os estereótipos atribuídos pelo discurso colonial seriam antes contrafeitos (via ressignificação) do que desfeitos (via desconstrução). Noutros termos, o anticolonialismo constituiu, no limite, um corolário ideológico do próprio colonialismo a que se contrapunha por reagir à economia maniqueísta que distinguia a virilidade imperial e a feminilidade colonial em semelhante maniqueísmo, instaurando rígidos códigos de gênero em um nacionalismo anticolonial fincado na radicalização de assimetrias entre homens e mulheres ${ }^{3}$.

Assim, o projeto nacional irlandês foi auspiciado por uma militarização da cultura na qual o rifle (dispositivo masculinizado, alusivo a valentia, sangue e protagonismo) e o rosário (dispositivo feminizado, alusivo a candura, lágrima e coadjuvação) balizaram seus respectivos paradigmas de hombridade e feminilidade. Para tal, apropriou-se de repertórios discursivos criados pelo catolicismo para a legitimação de uma economia sacrificial que consistia, para os homens, na sua entrega pela causa nacional, e para as mulheres, na entrega de maridos, filhos e irmãos, sob garantia de que estes reaveriam sua hombridade ao se sacrificarem pela nação e aquelas ratificariam sua feminilidade ao incitá-los ao autosacrifício. Nesse sentido, a Igreja contribuiu decisivamente para o projeto de nação, pois, além de conferir sacralidade à

\footnotetext{
${ }^{1}$ No inglês, o neologismo to other (construir o outro como diferente) tem sido largamente utilizado em estudos sobre processos de construção da diferença (e.g. de gênero, raça, classe). Como, em português, também utilizamos o substantivo "alteridade", mas não dispomos de um verbo que designe o processo de construção da "alteridade", empregamos o neologismo "alterizar" e o termo "alterização" para nos referirmos a esse processo.

2 Têm-se, em inglês, as formas genre (gênero textual) e gender (categoria social pautada na dualidade masculino/feminino), ao passo que no português o termo gênero abrange ambas as conotações. Traduzimos o verbo to gender (atribuir valor de gênero) como "generizar" pela ausência de um equivalente adequado em português.

${ }^{3}$ Cf. SOUSA, Raimundo Expedito dos Santos. Da Feminização à Remasculinização: Gênero e Raça na Dialética Angloirlandesa. Dissertação (Mestrado em Estudos Literários). 361ff. Programa de Mestrado em Letras, Universidade Federal de São João del-Rei, São João del-Rei, 2013.
} 
ideologia sacrificial, também atuou como instância de criação e distribuição de códigos de gênero inspirados nas figuras de Jesus e Maria, com vistas à naturalização de uma economia de gênero pautada na concatenação entre o sacrifício másculo e o sofrimento feminino ${ }^{4}$. Levando em consideração esse panorama, examinamos, mediante pesquisa em fontes primárias, como as lideranças nacionalistas "alterizavam" ${ }^{5}$ as mulheres que cobiçavam agência no espaço público, notadamente as feministas, que antepunham sua agenda à do nacionalismo, e as republicanas, que ousavam defender a Irlanda antes com o rifle do que com o rosário.

\section{Nacionalismo e ideologia de gênero}

O argumento de que os sexos possuíam faculdades assimétricas, porém complementares, emprestava ao falocentrismo do projeto nacional irlandês um romantismo insuspeitado, como explicitava um ideólogo ao afirmar que

womanhood is [...] valuable to Ireland as an indirect rather than a direct force. It furnishes a light of idealism in which the manhood of the nation sees many incentives for the maintenance of its patriotic endeavours and the deeds it inspires by its spirit-influence are far more important than anything that results from its own direct participation in acts that are more suited for manly hands to $\mathrm{do}^{6}$.

Reduzidas à função inspiradora, as mulheres seriam valorizadas conforme mobilizassem os homens, à sombra dos quais teriam supostamente mais a contribuir para o projeto nacional do que pela atuação na cena pública. Não bastava ao êxito do código sacrificial que os homens fossem persuadidos a almejar o sacrifício como valor supremo; era preciso também convencer as mulheres de que não deveriam cobiçá-lo por ser extrínseco à sua natureza e, mais ainda, de que eram indefesas e, portanto, dependentes daqueles. Afinal, se as mulheres se defendessem sozinhas, quem precisaria se sacrificar por elas? Noutros termos, como os homens exibiriam o heroísmo necessário à ratificação de sua hombridade se não houvesse vítimas dependentes de sua defesa? Por isso, se o horizonte ideológico do nacionalismo pode ser sintetizado pela metáfora da dupla face de Jano, na qual um rosto se volta para o passado

\footnotetext{
${ }^{4}$ SOUSA, op. cit..

${ }^{5}$ No inglês, o neologismo to other (construir o outro como diferente) tem sido largamente utilizado em estudos sobre processos de construção da diferença (e.g. de gênero, raça, classe). Como, em português, também utilizamos o substantivo "alteridade", mas não dispomos de um verbo que designe o processo de construção da "alteridade", empregamos o neologismo "alterizar" para nos referirmos a esse processo.

${ }^{6}$ CASSIDY, J. The Women of the Gael. Boston: Stratford Company Publishers, 1922, p. 4-5.
} 


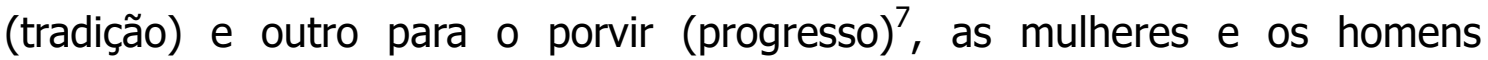
deveriam ser, respectivamente, conservadoras enquanto guardiãs de princípios que se queriam imutáveis e inovadores enquanto agentes do progresso imprescindível ao desenvolvimento da nação.

Dada a necessidade de convencer as mulheres de sua coadjuvação no ethos sacrificial, novamente a inflexão católica se mostraria útil ao instituir a Virgem Maria como um paradigma de feminilidade que a religião protestante, hostil à mariolatria, deveria buscar em outras figuras. O culto à Virgem, desenvolvido tardiamente no catolicismo e tratado com reservas pelo magistério de uma Igreja falocêntrica para não eclipsar a trindade masculinizada nem reavivar o culto pagão às deusas da fertilidade, foi revigorado no século XIX com o recrudescimento do marianismo nos países católicos, haja vista que apenas em 1854 foi instituído o Dogma da Imaculada Conceição, por Pio IX, que culminaria, em 1950, no Dogma da Assunção, por Pio XII ${ }^{8}$. Na Irlanda, país que vivenciou uma revolução devocional particular em meados do Oitocentos sob os auspícios do catolicismo ultramontano, a Igreja, em face da miséria instalada após a Grande Fome, ergueu a Virgem como alento espiritual para os sobreviventes, que a adotaram como uma Mãe que os guardaria sob seu manto protetor, e como exemplo de castidade para viúvas e solteironas ${ }^{9}$.

Investida de um conjunto de atributos cristalizados no imaginário ocidental cristão, Maria fornecia um perfil identitário pronto, que bastaria ser associado às irlandesas como se lhes fosse peculiar. Assim, enquanto o discurso colonial representava as nativas como dissolutas e metaforizava a ilha como amante do império, diversos ideólogos anticolonialistas retrucavam tais insultos pela celebração da suposta posição destas como as mulheres mais castas do mundo, quer por realmente crerem nessa marca distintiva, quer pelo fito de as pressionarem, pela lisonja, a corresponder a essa atribuição. Desse modo, vangloriavam-se superlativamente da mulher irlandesa como "o tipo mais excelso do mundo em feminilidade e virgindade ${ }^{\prime 1011}$, que possivelmente ganharia "o primeiro prêmio do mundo em modéstia e purezavirginal"12. Evidentemente, a mulher irlandesa, tal como descrita pelos nacionalistas, não passava de uma idealização a partir do modelo mental da Virgem, como se pode depreender pela forma como um padre a definia:

An Irish mother! She is foremost among the hidden saints of earth. A follower of Christ, whose cloister is within the four walls of the home, wherein she reigns as a queen! [...] A ruler for Christ, who draws her subjects to her sanctity and love. Her toil-worn hands that clasp the old brown rosary are eloquent of

\footnotetext{
${ }^{7}$ NAIRN, T. Faces of Nationalism: Janus Revisited. London: Verso, 1997.

${ }^{8}$ SANT'ANNA, A. R. O canibalismo amoroso: o desejo e a interdição em nossa cultura através da poesia. São Paulo: Brasiliense, 1985.

${ }^{9}$ LARKIN, E. The Devotional Revolution in Ireland, 1850-75. American Historical Review, v. 77, n. 3, p. 625-652, 1972; INNES, C. L. Woman and Nation in Irish Literature and Society, 18801935. Athens: University of Georgia Press, 1993.

${ }^{10}$ SPARLING, C. The Irish-Canuck-Yankee. Chicago: M. A. Donohue, 1913, p. 45.

11 Tradução nossa. Todas as traduções de citações em língua estrangeira são de nossa autoria.

12 CASSIDY, op. cit., p. 206.
} 
strength to seize and lift to God all souls they meet; her lips are molded to lines of peace by years of unending prayer and murmured benisons over sleeping babes; upon her brow eternal calm and resignation sit enthroned; her eyes are lit by the light of serene confidence, that tells of a heart secure in the friendship of $\operatorname{God}^{13}$.

Essa irlandesa idealizada, cujos traços físicos mantêm relação especular com sua disposição anímica, rompe com a clivagem entre alma e corpo, espiritualidade e carnalidade, que na ideologia cristã caracteriza o ser humano cindido entre as forças do Bem e do Mal. Porém, uma vez que apenas a Virgem teria sido poupada do estigma partilhado por todas as mulheres, relacioná-la à irlandesa implicava impor a esta última um padrão comportamental inexequível, já que era impossível preencher conjuntamente dois quesitos de feminilidade inconciliáveis, a virgindade e a maternidade. Dada a sua incapacidade de cumprir à risca o padrão mariano, as mulheres poderiam, se tanto, aproximarse de Maria, e essa incompletude facilitava um rígido controle sobre sua conduta, fazendo-as se envergonharem de cada ato que as distanciasse ainda mais da Virgem. Portanto, atribuir o conservadorismo como valor inato à mulher irlandesa implicava condenar como anti-femininas aquelas que não 0 expressassem, assim como conceber a mulher "normal" como sexualmente anestesiada facilitava a ingerência sobre sua sexualidade e a condenação da mulher pública, de forma que qualquer reivindicação política seria tomada como deslealdade à nação e qualquer manifestação erótica como negação da natureza. Se bem que Maria assegurasse às gaélicas um discreto empoderamento na medida em que as limitações do cosmo doméstico seriam compensadas pelo axioma de que detinham o mundo em suas mãos e podiam manipulá-lo com seu rosário, seu enaltecimento como gestoras soberanas do lar constituía uma forma não conflituosa de intimidá-las para que não cobiçassem a esfera pública. Da mesma forma, o elogio do espaço privado como moralmente superior ao público não era mais do que um engodo que tentava inverter hierarquias de poder ao tempo em que as acentuava, haja vista que, em patente contradição, a "rainha" não usufruía os mesmos direitos de cidadania que seus súditos, como se verá mais adiante.

Respaldado pelo álibi de que a avidez por emancipação política era estranha à natureza das hibérnicas, conservadoras por excelência, um intelectual nacionalista celebrava, menos por certeza do que por retórica, que suas patrícias não eram "politicamente inclinadas" e, ao invés de cobiçarem ocupações masculinas, desejavam "uma vida mais feminina"14. Um segundo definia a mulher irlandesa como dotada de um "conservadorismo instintivo" que a resguardava "contra todas as tentações de abandonar o lar por atividades mais 'atualizadas' fora dele ${ }^{\prime 15}$. Comentários ufanistas como esses

\footnotetext{
${ }^{13}$ LOCKINGTON, W. The Soul of Ireland. New York: The Macmillan Company, 1920, p. 120.

${ }^{14}$ RUSSELL, G. Co-operation and nationality. Dublin: Maunsel and Company, 1912, p. 67.

${ }^{15}$ CASSIDY, op. cit., p. 34.
} 
escamoteavam, na descrição de comportamentos supostamente característicos das gaélicas, a prescrição de como estas deveriam se portar, de forma que o elogio operava como um mecanismo de controle subliminar, pois partir do pressuposto de que as irlandesas já eram virtuosas as pressionava a responder às expectativas sociais em torno de sua conduta.

Se as descrições lisonjeiras não tivessem, subliminarmente, um caráter prescritivo, não se precisaria lançar mão de estratégias materiais para enquadrar as mulheres em um padrão comportamental supostamente intrínseco a elas. Uma das implicações da Revolução Industrial, a clivagem entre a casa e o local de trabalho e, por conseguinte, a exclusão da mulher da economia formal por não produzir mais-valia, repercutiu tardiamente na Irlanda, às voltas com uma economia agropastoril até meados do século XX. Contudo, a estratificação de gênero ocorreu mesmo nesse modo de produção em um duplo movimento calcado na adoção de medidas que aspiravam à masculinização do espaço público e feminização do doméstico mediante restrição da atuação das mulheres pela compressão (e regulação) do espaço doméstico e ampliação da atuação dos homens pela extensão (e regulação) do público. Se, em parte, a retirada maciça das mulheres do campo para o trabalho doméstico ao final do Oitocentos decorreu da rarefação do labor agrícola subsequentemente à Grande Fome, em parte se deveu ao empenho de reformistas rurais com vistas a consolidar um ideal de nação "generizada" binariamente, insuflando-as ao confinamento doméstico e à retomada e perpetuação de tradições pré-coloniais. Com vistas ao encapsulamento da mulher na célula familiar, reformistas sociais conferiam atratividade ao seio doméstico por força de iniciativas como, por exemplo, cruzadas contra casas mal-cuidadas, certames com premiação para a cottage mais impecável, concursos de gulodices, lições de economia doméstica e mesmo admoestações contundentes, como a do austero George Russell: "Estamos envergonhados das mulheres irlandesas porque elas não têm nenhum orgulho das artes femininas e não têm dado nenhuma contribuição à mesa de jantar do mundo senão o cozido irlandês" ${ }^{\prime 16}$.

Se a conjuntura militar de luta pela independência nacional havia trazido as mulheres à arena pública, sobretudo como mão de obra substitutiva para manutenção da engrenagem capitalista, uma vez restaurada a ordem civil eram reconduzidas aos antigos papéis, quer sob efeito de discursos laudatórios acerca da maternidade e da domesticidade, quer via medidas coercitivas como aquelas adotadas pelo governo, que oferecia nos anos 1930 subsídios às indústrias que contratassem mais homens do que mulheres. Também com vistas a restringir sua agência, foram promulgados diversos Atos que, na contramão do liberalismo, acentuavam a intervenção estatal a fim de assegurar o monopólio masculino na esfera pública e a sujeição das mulheres às funções reprodutivas, deslocando-as do trabalho fabril para o trabalho de parto. Destes, - Civil Service Amendment Act (1925) restringia seu acesso ao mercado de trabalho, o Matrimonial Act (1925) vetava o divórcio, o Juries Act (1927) as

\footnotetext{
${ }^{16}$ RUSSELL, G. Home Life in Ireland - A Challenge to Irishwomen. Irish Homestead, 1 de junho de 1907, p. 428.
} 
excluía do serviço jurídico e o Censorship of Publications Act (1929) Ihes negava acesso a informações sobre controle da natalidade. Essa miríade de estratégias que visavam formar um cordon sanitaire entre as esferas masculina e feminina culminaria, em 1937, com a Bunreacht na hÉireann (Legislação Fundacional da Irlanda), cujo controverso artigo 41 dispunha sobre os planos estatais para a mulher na República:

41.2.1 In particular, the State recognises that by her life within the home, woman gives to the state a support without which the common good cannot be achieved. [...] 41.2.3. The State shall, therefore, endeavour to ensure that mothers shall not be obliged by economic necessity to engage in labour to the neglect of their duties in the home ${ }^{17}$.

Além de aproximar os substantivos "mulher" e "mãe" em relação sinonímica, o discurso constitucional se apresentava como instância defensora dos direitos femininos, propondo um pacto implícito no qual o Estado se comprometia a salvaguardar os direitos da mulher-mãe, que, por sua vez, deveria retribuir com seu zelo pelo "bem comum" de toda a nação, sob garantia de que em nenhuma hipótese seria "forçada" a deixar seu reino doméstico.

\section{A feminista como alteridade}

Embora o nacionalismo irlandês fosse pautado no isolamento cultural com vistas ao resgate da cultura pré-colonial, a Irlanda também sofreu impacto do sufragismo em sua cultura. Inspirado em sua congênere inglesa, 0 feminismo irlandês era concebido como empecilho ao projeto de remasculinização, já que, como os padrões de gênero se constituem dicotomicamente, se as mulheres deixassem de ser hiperfemininas, consequentemente os homens não seriam hipermasculinos. Assim, enquanto as suffragettes inglesas enfrentavam resistência da ordem instituída, as irlandesas encaravam obstáculos adicionais, pois, em um nacionalismo animado por teorias conspiratórias acerca de ameaças estrangeiras à moralidade gaélica, 0 sufragismo era tomado como um anglicismo que, se não extirpado, arruinaria a cultura nativa. Haja vista a denúncia de um ideólogo quanto ao efeito danoso do influxo do feminismo na Irlanda por distrair as mulheres de seu compromisso no projeto nacional:

With our language dying, our traditions fading, our faith paling, the landmarks of our nationality disappearing around us one by one, has the Irishwoman's money and time and energy and place in her heart for a fight for a class. The rights of a class

\footnotetext{
${ }^{17}$ IRELAND. Constitution of Ireland. Dublin: Government Publications Office, 1937, p. 11.
} 
when the issue of a nation's existence is at stake! [...] The suffrage movement is turning the thoughts of the average Irishwoman Englandwards. That is the greatest danger in the present state of this country ${ }^{18}$.

A identificação do sufrágio feminino como o maior desafio a ser enfrentado pelas lideranças nacionalistas reforça a incompatibilidade entre nacionalismo e feminismo em um horizonte ideológico no qual as sufragistas eram consideradas desleais à nação não apenas pelo suposto desdém frente à degeneração da cultura nativa como por sua filiação com os ideais das feministas metropolitanas quando deveriam se opor incondicionalmente a tudo quanto proviesse da Inglaterra.

Como os homens precisavam provar sua virilidade subestimada pelo império, o cumprimento dos quesitos para aquisição da hombridade se tornaria ainda menos exequível se a mulher se "masculinizasse", embaralhando os papéis de gênero. Por isso o repúdio à adesão das mulheres aos inventos da modernidade, tais como o triciclo e a bicicleta, meios de locomoção considerados impróprios para as mulheres não apenas por serem incompatíveis com seu vestuário, mas, sobretudo, porque facilitavam seu trânsito pela arena pública. Por isso, a crescente voga desses veículos entre elas causava desconforto ao atenuar diferenças de gênero, como se vê na celeuma provocada pelas primeiras triciclistas na Irlanda, segundo relato de um jornal esportivo em 1889:

Through a distant town in the South-west of Ireland there passed a member of the Ladies' CC [Cycling Club], and the good people, unaccustomed to such a sight, rushed to their doors and windows, and stared with all the stare in their power. Now, it so happened, that in the same town there was a circus, and the clown was proceeding through the streets [...] when [...] the fair tricyclist got into that crowd, and quickly became the cynosure of all eyes, and it was not until she had gone some distance that she perceived that she had ousted the clown, the people evidently believing that she belonged to the circus also, and that she was much the most interesting object to follow ${ }^{19}$.

O episódio em que uma mulher é confundida como atração circense e, sobretudo, como uma atração mais curiosa do que um palhaço é sintomático de como a emancipação feminina era recebida como um contra-senso que, ao transgredir acepções de feminilidade convencionais, adquiria efeito cômico. A ultrapassagem de fronteiras espaciais pela Nova Mulher, capaz de percorrer longas distâncias, constituía uma medida de sua ruptura de fronteiras simbólicas entre os gêneros, atemorizando guardiões do patriarcado, como se percebe no discurso de um memorialista alarmado com sua "invasão" nas diferentes esferas sociais:

\footnotetext{
${ }^{18}$ LAEGH. Matters of the Moment. The Catholic Bulletin and Book Review, v. II, 1912, p. 791.

${ }^{19}$ IRISH CYCLIST AND ATHLETE. Editorial, 10 de julho de 1889, s.p.
} 


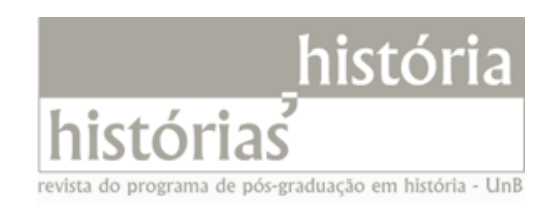

The lady legion in Kildare numbers its fifties and sixties; but in what department of life does not the lovely woman take the lead and keep it? [...]. Indeed, one of the phenomena of the second half of the century is the female usurpation of the privileges and prerogatives of men, and her general ascendency over the stronger and stupider sex, who, according to recent judicial decisions, have ceased to be "the head of the wife"20.

Ao identificar a mobilização das mulheres como um "fenômeno" emergente na segunda metade do Oitocentos, desconsiderando o histórico de engajamentos feministas, o ideólogo a concebia como um modismo instalado ex nihilo e, desse modo, a despolitizava ao negar sua historicidade. Também o substantivo coletivo "legião" caracterizava a irmandade suffragette como uma corporação que avançava vertiginosamente, apoderando-se de tudo quanto pertencesse aos homens, deixando entrever o temor da perda de prerrogativas até então não ameaçadas, já que era recorrente a crença de que o sufragismo instaurava uma ordem social anômala que ascendia a mulher $e$, por conseguinte, destronava o homem.

Entre os literatos, o escritor William Butler Yeats simbolizava a repulsa pela Nova Mulher, pois, à maneira dos românticos, idealizava a feminilidade passiva, mas se interessava por mulheres fálicas como Maud Gonne, motivado pelo desafio de adestrá-las conforme o paradigma de feminilidade vitoriano. Dentre suas diversas tentativas de dissuadi-la do ativismo político, o escritor se valia do desgastado argumento de que a mulher dedicada ao intelecto era subtraída de sua feminilidade. Ao compará-la à irmã, obediente aos padrões de gênero vitorianos, argumentava: "Você não cuida de si como faz Kathleen, tanto que ela parece mais jovem do que você; seu rosto está cansado e magro [...]. Por que não se casa comigo e desiste dessa faina trágica para levar uma vida pacífica?" ${ }^{\prime 21}$. Conforme explicaria em um de seus volumes autobiográficos, feminilidade e racionalidade eram incompatíveis:

Women, because the main event of their lives has been giving themselves and giving birth, give all to an opinion [...]. Men take up an opinion lightly [...] but to women opinions become as their children or their sweethearts, and the greater their emotional capacity the more do they forget all other things [...]. At last the opinion is so much identified with their nature that it seems a part of their flesh becomes stone and passes out of life ${ }^{22}$.

\footnotetext{
${ }^{20}$ MORRIS, M. Memini or Reminiscences of Irish Life. London: Harrison \& Sons, 1892, p. xxv.

${ }^{21}$ GONNE, M. A Servant of the Queen. London: Victor Gollancz, 1938, p. 330.

${ }^{22}$ YEATS, W. Dramatis personae. London: The Macmillan Company, 1936, p. 341.
} 
Sob a premissa de que as mulheres, porque condicionadas à doação, dão tudo de si a uma causa, incorrendo em exagerado investimento afetivo, o poeta compreendia que o intelectualismo Ihes seria então prejudicial, pois a tomada de posições políticas categóricas as tornaria fanáticas e incapazes de manter um necessário distanciamento da causa que propugnavam, já que a internalizariam como parte do seu ser.

Yeats era secundado por seu pai, o pintor John Butler Yeats, cuja oposição à Nova Mulher era manifesta no ensaio The Modern Woman: Reflections on a New and Interesting Type, no qual a caracterizava como uma anomalia da modernidade. Em descrição que informava menos acerca da mulher do que dos preconceitos do ideário patriarcal, o artista procurava despolitizá-la, representando-a como uma narcisista que, motivada pelo desejo de visibilidade no lugar de uma agenda consistente, não sabia ao certo o que desejava e só mantinha sua ilusão de emancipação porque ignorava sua limitação intelectual e seu sexo, que de outro modo denunciariam sua predestinação ao subjugo:

She may be in a minority, yet she is not difficult to discover, for she is most active, showing herself everywhere. Nor is it difficult to describe her, since she spends much of her time in describing herself. In the first place, like the orator, she is made rather than born; indeed, she is herself a good deal of an orator, always being ready to harangue her friends, explaining and enforcing her ideas. [...] Self-improvement is her passion; improvement in what direction? you will ask. She herself does not know. Meantime she insists on absolute personal liberty [...]. That she may be free she places a ban on the senses and upon sex; either of these would put her back under subjugation. [...] At the same time, while resolved on liberty she does not forget that she is born into a business community; therefore she has adopted the business man's creed efficiency: "Whatsoever thou doest, do it with all thy might."23.

Antipática à natureza, que em vão "grita dentro dela"24, divorciada de seus atributos naturais, como a doçura e o altruísmo, e ávida por aquiescência social e êxito profissional, a mulher moderna, sob esse prisma, despojava-se de sua essência feminina, tanto que, outrora "o maior dos mistérios do mundo", tornara-se tão previsível que perdera completamente seu encanto:

Now she is as easy to read as an old almanac. Watch her as she paces Fifth Avenue, with her businesslike air. How bright her eyes, and yet hard as jewels! Her smile how thin-lipped! and her figure that of a young athlete. Her mode of dress and of personal array, how smart and efficient and almost military! She is the very embodiment of briskness, and of commanding

\footnotetext{
${ }^{23}$ YEATS, J. Essays in Irish and American. Dublin: The Talbot Press Ltd.; London: T. Fisher Unwin Ltd., 1918, p. 63-64.

${ }^{24}$ YEATS, op. cit., p. 65.
} 
decision. But all the lines of allurement are vanished, and she no longer undulates with slow grace. She is not feline, neither is she deerlike; and she no longer caresses, for her voice is as uncompromising as her style of dress. The ordinary man [...] has always despised the arts of pleasing, until some charming woman has taken him in hand; but the modern woman has ceased to instruct him, and has become his imitator, so that her manners are almost as intimidating as those of the successful business $\operatorname{man}^{25}$.

Numa atmosfera de insegurança quanto a um iminente colapso social fomentado pelas vicissitudes da modernidade, os comentários acerca das vestimentas da mulher moderna, caracterizadas sardonicamente como imitações grosseiras do vestuário masculino, procuravam inscrever sua luta política como mera ganância de mimetizar os homens e não como busca de expansão de seu campo de participação pública. Desse modo, o escarnecimento do aspecto físico reduzia a feminista a uma aberração de gênero, situada na liminaridade entre a mulher, da qual se distanciava, e o homem, do qual aspirava se aproximar, e, como ambos os objetivos seriam inexequíveis, essa figura intersticial nem se distinguia completamente da primeira nem se igualava ao segundo de todo. Essa caracterização sugeria que a mulher moderna, não mais identificável à natureza, tornara-se um construto artificial e, não mais ocupando socialmente um epicentro distinto do homem, deixara de exercer a função primordial de instruí-lo a um cavalheirismo que coroasse sua hombridade. Se seu grande mérito consistia em representar um enigma para o homem e, assim, instigar suas faculdades imaginativas, servindo-Ihe de inspiração nas Letras e Artes, a mulher não teria existência própria senão em virtude do aprimoramento masculino. Portanto, a abdicação dessa prerrogativa aparentemente sobre-humana era interpretada como prova de insensatez, daí o argumento de que a mulher moderna, governada pelo egoísmo, "desceu ao nosso nível", tornando-se "um de nós"26. Nessa falsa hierarquia na qual o que está acima tem menos poder do que o que está abaixo, a mulher, ao descer à condição anódina do homem, desestabilizava exatamente a posição masculina de poder.

Sob o recorrente argumento de que a mulher contemporânea se masculinizava repousava o temor de que a atenuação de polaridades de gênero desestabilizasse a própria masculinidade, dependente de uma exterioridade constitutiva para adquirir significado em uma equação na qual quanto mais femininas fossem as mulheres, mais másculos os homens. O feminismo, precisamente por questionar tais polaridades, constituía ameaça para homens interpelados a ratificar uma condição máscula que não prescindia da diferenciação da feminilidade via negativa, de modo que um dos perigos da mulher moderna consistia em evidenciar a instabilidade dos códigos de gênero.

\footnotetext{
${ }^{25}$ YEATS, op. cit., p. 67-68.

${ }^{26}$ YEATS, op. cit., p. 71.
} 
Tal como na Inglaterra, onde várias mulheres letradas - incluindo-se as escritoras Charlotte Brontë, Elizabeth Browning, George Eliot e Christina Rossetti - se opunham veementemente à campanha pelo sufrágio feminino por duvidar da aptidão de seu gênero ao exercício da política ou por considerar que havia pautas mais prementes na agenda das mulheres ${ }^{27}$, na Irlanda as intelectuais mais reacionárias atuavam como cúmplices do regime falocrático na medida em que pressionavam os homens à masculinidade hegemônica e condenavam aquelas que aspiravam a outra emancipação que não fosse a independência do país. Ao tempo em que as suffragettes inglesas podiam se ocupar com a luta por acesso à instrução universitária, ao instituto do divórcio e às profissões liberais, as irlandesas, devido à especificidade da experiência colonial, deveriam conciliar o sonho de emancipação feminina com aquele, não menos premente, de emancipação política da nação. Duplamente atraída pelo nacionalismo e pelo feminismo em um movimento pendular entre duas agendas dissonantes, Constance Markievicz optou por priorizar a primeira ao creditar a subordinação das mulheres à colonização e crer que sua cidadania seria conquistada automaticamente após a descolonização, tal como explicou em conferência na Student's National Literary Society ao instruir as mulheres para que não se engajassem em lutas sociais desnecessárias e prejudiciais à unidade nacional:

Fix your mind on the ideal of Ireland free, with her women enjoying the full rights of citizenship in their own nation, and no one will be able to sidetrack you, and so make use of you to use up the energies of the nation in obtaining all sorts of concessions - concessions too, that for the most part were coming in the natural course of evolution, and were perhaps just hastened a few years by the fierce agitations to obtain them ${ }^{28}$.

A crença de que os direitos de cidadania seriam amealhados pelas mulheres tão logo fosse assegurada a autonomia política era alimentada pelo próprio ideário nacionalista. Calcado numa ideologia unificadora, o nacionalismo atraía grupos subalternos, dentre os quais as mulheres, induzindo-as a crerem que sua micropolítica seria incorporada à macropolítica nacionalista ou que, estando a opressão de gênero vinculada à colonização, adquiririam os direitos que pleiteavam automaticamente após a implantação do Estado Livre. Graças à internalização desse axioma, várias mulheres letradas não só aceitavam de bom grado os encargos delegados ao gênero feminino como se mostravam eficientes delatoras em relação a outras mulheres. Uma vez que toda representação consiste numa construção a partir de uma determinada posição no interior das relações de poder, os ideólogos anti-sufragistas não caracterizavam suas conterrâneas mediante representações distorcidas que, se empreendidas por uma delas, seriam mais autênticas. Afinal, se a representação é antes uma

\footnotetext{
${ }^{27}$ HIMMELFARB, G. The De-Moralization of Society: From Victorian Virtues to Modern Values. New York: Alfred A. Knopf, Inc., 1994.

${ }^{28}$ MARKIEVICZ, C. Women, Ideals and the Nation. Dublin: Inghinidhe na hEireann, 1909, p. 9.
} 
construção de sentidos do que uma reprodução especular, as mulheres bem poderiam assumir postura análoga à dos homens mais misóginos se inseridas em seu regime de significação. De fato, o discurso que enaltecia seu contributo na arquitetura da nação a partir da base a fim de obter sua adesão à causa nacional induzia o reacionarismo daquelas intelectuais que, mesmo posicionadas em favor do gênero feminino, endossavam a convencional cisão de gênero entre esferas sociais. Dentre outras, Mary Butler relacionava a contribuição das mulheres no resgate da língua gaélica ao afastamento dos debates públicos e ao retiro doméstico:

Now the women of our race are dignified and decorous; they shrink from mingling in a melee, and retiring into the inner courtyard, they leave the scene of strife in the outer world to the sterner sex. They may, therefore, think that in this language war they have no place, but they are mistaken, for it is warfare of an special kind, warfare which can best be waged not by shrieking viragoes or aggressive amazons, but by gentle, lowvoiced women who teach little children their first prayers, and, seated at the hearth-side, make these around them realise the difference between a home and a dwelling. [...] Let it then be thoroughly understood that when Irishwomen are invited to take part in the language movement they are not required to plunge into the vortex of public life. No, the work which they can best do is work to be done at home ${ }^{29}$.

No limiar do século $X X$, o desafio crucial das irlandesas consistia em se livrar não tanto do opressor, instância coercitiva associada ao homem, mas do opressor internalizado nelas próprias, pois mesmo as mulheres investidas de autoridade discursiva na ordem simbólica se posicionavam, não raro, sob os limites epistêmicos de uma formação discursiva falocêntrica. Daí a poeta Katharine Tynan, na conclamação "A Trumpet Call to Irish Women", escrita em comemoração ao Estado Livre recém-implantado, definir nos seguintes termos o papel da mulher na nação que se constituía: "O anseio de nossa nação não é pela amazona [...]. É pela mulher conservadora, zeladora de todas as santidades, de todas as seguridades, de todas as salvaguardas da Casa da Vida" ${ }^{\prime 30}$. Se bem que a amazona fosse, potencialmente, um símbolo de resistência contra um discurso colonial que concebia a Irlanda como uma mulher dependente da tutela masculina, esse símbolo mitigava ainda mais a hombridade dos irlandeses, valor priorizado pela agenda nacionalista. Seguras de que a amazona conspurcava o gênero feminino - quando, a rigor, fazia-o com o masculino -, ambas as escritoras a refutavam ao considerar que predicados como a combatividade e a avidez por conquista eram não só toleráveis como desejáveis no homem, mas, na mulher, seriam faltas graves

\footnotetext{
${ }^{29}$ BUTLER, M. Irishwomen and the Home Language. Dublin: Gaelic League, 1901, p. 3.

30 TYNAN, K. A Trumpet Call to Irish Women. In: FITZGERALD, William George (Ed.). The Voice of Ireland: a survey of the race and nation from all angles. Dublin: Virtue and Co., 1924, p. 174.
} 
porque a natureza a havia moldado para o reino do afeto a fim de contrabalançar a racionalidade masculina.

Ainda mais radical, a escritora Nora Tynan O'Mahony declarava abominação pelas suffragettes em manifesto, publicado no jornal católico Irish Monthly, contra a invasão do modismo Nova Mulher na Irlanda. Certa de que a honra vinculada à domesticidade estava em vias de extinção "nestes dias degenerados de sufragetismo (sic) militante e similar idiotice, se não perversidade", a autora advertia as mulheres contra a "distorção gradual de sua natureza", insuflada "pelos guinchos histéricos da irmandade suffragette" ${ }^{\prime 31}$. Também apontava o sufragismo como contra-senso, pois a mulher, ao almejar aquiescência social no mundo externo, perdia seu status "como incontestável senhora e rainha do lar", levando ao "destronamento da mãe e seu nenê, a Nossa Senhora e a Criança, que deveriam ser os primeiros e mais sagrados objetos de toda casa" ${ }^{\prime 32}$. Para intelectuais como O'Mahony, uma vez que as irlandesas já possuíam seu espaço de atuação e o prestígio conquistado pela excelência com que o gerenciavam, aquelas imprevidentes que abrissem mão desse espaço perigavam não obter o mesmo êxito na arena pública e ainda perder a hegemonia na esfera privada. Era mais seguro, portanto, considerar que a Nova Mulher, impelida por influências extrínsecas à cultura nativa a disputar com os homens um espaço que não o seu, fazia-o sob pena de perder a reputação como esposa e mãe. Sob essa crença, rejeitavam qualquer desvio dos padrões comportamentais femininos, partindo da premissa de que a mulher representava o elemento conservador da cultura nacional. Se bem que O'Mahony considerasse a praticidade e o conforto do vestuário adotado pela mulher moderna, seu superego patriarcal se impunha ao lembrá-la da inadequação deste à natureza feminina:

[T] he regrettable lack of femininity, of sweet, gracious, dignified womanliness, not only in modern woman's manners but in her dress, all tend to bring her down to a lower level in masculine eyes than she ever sank before. The mannish cut of the modern woman's scanty garments, the short skirts, the liberal display of ankle, the often bared throat and neck [...], the jaunty set of her hat jammed down to one side, and completely covering her hair and her eyes - it may be convenient and comfortable, but it certainly is not womanly ${ }^{33}$.

A indistinção entre o discurso de Markievicz, Butler, Tynan e O’Mahony e aquele dos guardiões do falocracismo indica que posições políticas hegemônicas eram articuladas de modo que as irlandesas as identificassem como suas, já que o padrão de feminidade atingiria pleno êxito quando introjetado pelas mulheres, que se tornariam, elas próprias, vigilantes de si e de outrem. Inseridas numa episteme cujo horizonte ideológico não lhes facultava vislumbrar outras possibilidades de agência que as estabelecidas pela ideologia

\footnotetext{
${ }^{31}$ O'MAHONY, N. The Mother. The Irish Monthly, 91, 1913, p. 529.

${ }^{32}$ O'MAHONY, op. cit., p. 530.

${ }^{33}$ O'MAHONY, op. cit., p. 530.
} 
hegemônica, essas intelectuais interpretavam as incursões da mulher pela esfera pública como deterioração de valores que a haviam consagrado socialmente. Todavia, afirmar que reproduziam o discurso androcêntrico simplesmente porque alienadas sob seu efeito ideológico seria desconsiderar por completo sua capacidade de negociação. $O$ fato de algumas mulheres serem mais suscetíveis à ideologia dominante do que outras tinha um caráter pragmático, pois essas intelectuais afinadas com a falocracia obtinham algum dividendo, haja vista sua prerrogativa de participação no debate público, ao tempo em que diversas das mulheres em nome das quais estas advogavam eram despojadas de qualquer isonomia.

\section{A republicana como alteridade}

Segundo a ideologia dominante, se as mulheres cooptadas pela campanha sufragista desobedeciam seu papel de gênero ao negligenciar a causa nacional, aquelas que se excedessem em sua participação no nacionalismo para além das tarefas delimitadas pela agenda nacionalista o fariam pela inobediência às limitações de sua natureza. De fato, em um nacionalismo que se queria viril, as mulheres que ousassem defender a nação com a arma em vez do rosário seriam antes adversárias que aliadas da causa nacional. Por isso o mesmo Presidente William Cosgrave que repreendeu um grupo de manifestantes republicanas afirmando-lhes que, em vez de manusear armas, deveriam ter rosários em suas mãos, lamentou a participação de mulheres no nacionalismo militar em análise retrospectiva do primeiro ano de Estado Livre:

In England, fortunately for her, the 'Die-hards' are men [...]; but unhappily in Ireland the 'Die-hards' are women, whose ecstasies at their extremest can find no outlet so satisfying as destruction - sheer destruction ${ }^{34}$.

Sob impacto da psiquiatria vitoriana, notadamente a histerização de mulheres insurgentes contra padrões de feminilidade, uma forma de deslegitimar o ativismo das republicanas consistia em identificá-lo como agente patogênico e caracterizá-las sob o signo da insanidade, de forma a despolitizar sua atuação como resultante de impulsos irracionais. Partindo-se da premissa de que a mulher, devido à instabilidade de sua constituição cognitiva, seria governada pelo excesso tanto para o bem quanto para o mal, justificava-se que apenas a disfunção mental explicaria sua adesão a empreendimentos contrários à natureza de seu gênero e que seu envolvimento militar só poderia redundar em destruição. Prova disso é um relato oficial do Estado Livre, publicado no The Irish Independent de $1^{\circ}$ de janeiro de 1923 sob a manchete "Neurotic Girls",

${ }^{34}$ COSGRAVE, W. Mr. Cosgrave's Review. Irish Times, 1 jan. 1923, p. 11. 
referindo-se às republicanas engajadas no militarismo nos seguintes termos: "Moças neuróticas estão entre os mais ativos aderentes da causa irregular [republicana] [...]. Elas desfiguram os muros de Dublin com propagandas mentirosas e são ativas transportadoras de documentos, armas e munições" ${ }^{\prime 35}$.

Alguns opositores remontavam à mitologia greco-romana para encontrar uma figura que encapsulasse toda a monstruosidade contida na mulher que empunhasse o rifle em vez do rosário. Em homilia publicada no Cork Examiner, o Bispo Doorley instruía meninas a jamais aderirem ao engajamento militar sob pena de se transformarem em "Fúrias":

If I had a little girl friend who took up politics I would give up praying for her. Women who go around taking despatches and arms from one place to another are furies. Who would respect them or who would marry them? Never join a Cumann na mBan or a Cumann na Saoirse or anything else. Do your work as your grandmothers did before you ${ }^{36}$.

Sob um sistema de valores em que na respeitabilidade e no casamento residiam os bens supremos de uma mulher, aderir às forças armadas implicava despojar-se exatamente do respeito social e da possibilidade de ser desejada como esposa, convertendo-se em "víboras", metamorfose que implicava abdicar-se não apenas da feminilidade como da própria humanidade. $O$ fato de nem mesmo orações serem capazes de amansar as ativistas reforçava sua percepção como bestas irracionais cuja emulação as jovens deveriam evitar em prol de um modelo de identificação fincado na figura arquetípica da avó. Se em nível manifesto as "Fúrias" da mitologia grega, entidades demoníacas dotadas de cabeleira em forma de serpentes, configuravam um meio de aterrorizar as irlandesas, dissuadindo-as do militarismo, em nível latente constituíam um sintoma do terror suscitado pelas mulheres públicas, identificadas como figuras castradoras que, à semelhança da Medusa, estarreciam homens sob cuja pose varonil se disfarçava um concentrado teor de angústia.

Dentre as mulheres atuantes no nacionalismo militar, uma das mais proeminentes foi Constance Markievicz (1868-1927), cujo engajamento bélico incitava a indignação de seus contemporâneos por desviá-la de seu destino "natural" como ornamento e inspiração masculina. Diversos comentadores subestimavam sua consciência política, interpretando como resultado de empolgação irrefletida sua adesão a agendas em princípio incompatíveis (como o socialismo, o feminismo e o nacionalismo), como fez o escritor Sean O'Faolain, ao afirmar que a condessa "não tinha ideias inteligíveis, mas instintos ${ }^{\prime \prime 3}$. Todavia, o caráter mais perturbador de sua infração dos códigos de gênero consistia na ameaça à correlação entre armamento e virilidade em que se ancorava o programa de "revirilização" nacional. No apogeu de um nacionalismo que incompatibilizava feminilidade e militância e no qual a mulher

\footnotetext{
${ }^{35}$ IRISH INDEPENDENT. Neurotic Girls, 1 jan. 1923, s.p.

${ }^{36}$ DOORLEY. Women Who are Furies. Cork Examiner, 18 mai. 1925, p. 11.

${ }^{37}$ O'FAOLAIN, S. Constance Markievicz, or The Average Revolutionary. London: Jonathan Cape, 1934, p. 74.
} 
deveria trazer em punho o rosário, não o rifle, Constance era identificada como uma aberração, haja vista a forma caricatural com que sua rendição foi descrita por jornais como o Irish Times.

The Countess was in charge of the rebels at the College of Surgeons. Realising the hopelessness of the struggle, she offered to surrender [...]. The countess who had 120 men, walked out of the building at their head. She was dressed entirely in green, including green shoes. She walked up to the officer and saluting took out her revolver which she kissed affectionately and then handed it up ${ }^{38}$.

Ao representar a entrega do revólver como um erotizado gesto de despedida, a imprensa procurava deslegitimar a inserção da mulher no militarismo como motivada pela avidez por juissance e espetáculo, ridicularizar o fetichismo feminino e desacreditar o próprio Levante - que, como se sabe, não teve aceitação imediata - pelo fato de uma mulher ridiculamente vestida reger uma corporação de 120 homens. No entanto, gestos de escárnio como esse mal disfarçavam a insegurança quanto à possibilidade do revólver ser portado por uma mulher; afinal, Constance provocava desconforto não apenas por assumir um papel "masculino", mas porque, ao fazê-lo, punha em questão a fantasia de "revirilização", por comprometer a vinculação entre armamento e masculinidade.

\section{Considerações finais}

No projeto nacional irlandês, os nacionalistas estavam seguros de que o êxito da remasculinização do país dependia de uma cooperação entre os sexos, na qual ambos se complementassem de sorte que as potencialidades de um compensassem as deficiências do outro. Nesse sentido, a mulher que fugia a esse contrato social invertia a lógica que organizava as relações de gênero, comprometendo a um só tempo os códigos de masculinidade e feminilidade pela ameaça de descentramento que impunha à falocracia. Por isso a aversão dos intelectuais nacionalistas pelas figuras da feminista e da republicana, cujas respectivas formas de agência ameaçavam a política de revirilização, já que a masculinidade se definia em relação antitética e complementar com a feminilidade, de sorte que qualquer alteração nos padrões desta última desestabilizava os referenciais da primeira.

Se levarmos em conta a subalternidade das mulheres no projeto nacional irlandês, o crítico Luke Gibbons é impreciso ao generalizar que na Irlanda colonial "a população nativa inteira, tanto a masculina quanto a feminina,

${ }^{38}$ IRISH TIMES. Surrender of Countess Markievicz. 2 mai. 1916, s.p. 
partilhava da condição das mulheres no centro metropolitano"139. Ora, as especificidades da condição colonial tornavam as irlandesas relativamente mais subordinadas do que as inglesas e implicavam desafios adicionais ao feminismo em um país cuja elevação do nacionalismo anticolonial sobre outras formas de coalizão invalidava reivindicações feministas com tanto ou mais intensidade do que na metrópole. Ao tempo em que as suffragettes inglesas podiam se ocupar com a luta por acesso à instrução universitária, ao instituto do divórcio e às profissões liberais, as irlandesas, devido à especificidade da experiência colonial, deveriam coadunar o sonho de emancipação feminina com aquele, não menos premente, de emancipação política da nação, e diante desse duplo imperativo a mulher, instigada desde tenra idade ao altruísmo, acabava antepondo o segundo, que beneficiaria toda a coletividade, ao primeiro, que favoreceria seu grupo restrito.

Não bastasse isso, o falocentrismo da agenda nacionalista, franqueado pelo axioma de que a nação fora mutilada em sua hombridade, impôs obstáculos à participação das mulheres em um projeto de nação obcecado pela virilidade dos homens. Desse modo, as irlandesas eram subjugadas numa hierarquia de gênero doméstica que as excluía dos direitos à morte sacrificial e à vida plena, encurralando-as sob diferentes dispositivos de controle, a fim de que não ameaçassem um projeto de remasculinização que se esforçava para proteger as fronteiras da nação enquanto estabelecia fronteiras internas.

\section{Sobre os autores}

Raimundo Expedito dos Santos Sousa é doutorando em Teoria da Literatura e Literatura Comparada (linha de pesquisa Literatura, História e Memória Cultural) pela Universidade Federal de Minas Gerais (UFMG), onde desenvolve pesquisa sobre gênero e sexualidade, com financiamento da Fundação de Amparo à Pesquisa do Estado de Minas Gerais (FAPEMIG). E-mail: raimundo sousa@terra.com.br.

Adelaine LaGuardia é doutora em Literatura Comparada pela Universidade Federal de Minas Gerais (UFMG). Atualmente, é professora associada da faculdade de Letras da Universidade Federal de São João del-Rei (UFSJ), onde também atua no Programa de Pós-Graduação em Letras. Desenvolve e orienta pesquisas no âmbito dos Estudos de Gênero e Sexualidade. E-mail: adelaineufsj@gmail.com.

Recebido em 28 de fevereiro de 2015. Aprovado em 20 de julho de 2015.

${ }^{39}$ GIBBONS, L. Transformations in Irish Culture. Notre Dame: University of Notre dame Press, 1996, p. 20. 